Article

\title{
Environmental Pollution Effects of Regional Industrial Transfer Illustrated with Jiangsu, China
}

\author{
Guangxiong Mao ${ }^{1,2,{ }^{\dagger}}$, Wei Jin ${ }^{3, *+}{ }^{\dagger}$, Ying Zhu ${ }^{4}$, Yanjun Mao ${ }^{5}$, Wei-Ling Hsu ${ }^{1,2}$ (D) and Hsin-Lung Liu ${ }^{6, *}$ (I) \\ 1 School of Urban and Environmental Science, Huaiyin Normal University, Huai'an 223300, China; \\ gxmao123@126.com or 8199811008@hytc.edu.cn (G.M.); quartback@hotmail.com or \\ 8201811011@hytc.edu.cn (W.-L.H.) \\ 2 Key Research Base of Philosophy and Social Sciences in Jiangsu Universities-Research Institute of Huaihe \\ River Eco-Economic Belt, Huai'an 223300, China \\ 3 School of Sociology and Population Sciences, Nanjing University of Posts and Telecommunications, \\ Nanjing 210003, China \\ 4 Energy College, Chengdu University of Technology, Chengdu 610059, China; zhuying1203@outlook.com \\ 5 College of Geographical Science, Harbin Normal University, Harbin 150025, China; yjmao123@Hotmail.com \\ 6 Department of Leisure Management, Minghsin University of Science and Technology, \\ Hsinchu 30401, Taiwan, China \\ * Correspondence: kingwei@njupt.edu.cn (W.J.); hsinlung@must.edu.tw (H.-L.L.); \\ Tel.: +886-922225586 (H.-L.L.) \\ + Guangxiong Mao and Wei Jin contributed equally to this work.
}

Citation: Mao, G.; Jin, W.; Zhu, Y.; Mao, Y.; Hsu, W.-L.; Liu, H.-L. Environmental Pollution Effects of Regional Industrial Transfer Illustrated with Jiangsu, China Sustainability 2021, 13, 12128. https://doi.org/10.3390/su132112128

Academic Editor: Alessandra De Marco

Received: 12 October 2021

Accepted: 29 October 2021

Published: 3 November 2021

Publisher's Note: MDPI stays neutral with regard to jurisdictional claims in published maps and institutional affiliations.

Copyright: () 2021 by the authors. Licensee MDPI, Basel, Switzerland. This article is an open access article distributed under the terms and conditions of the Creative Commons Attribution (CC BY) license (https:// creativecommons.org/licenses/by/ $4.0 /)$.

\begin{abstract}
Industrial transfer is reshaping the geographic layout of industries and facilitating the transfer and spread of environmental pollution. This study employs the pollution transfer estimation method to discuss the environmental effect of industrial transfer. By compiling statistics on industries of a certain scale according to time-series data, the researchers compute the pollution load generated by industrial transfer and the difference in pollution emissions for each region and industry. Through the constructed evaluation model, the empirical scope is Jiangsu, which is the most developed industry in China. The results reveal that there is an apparent spatial hierarchy among the transferred industries in Jiangsu. Most industries transfer from the southern Jiangsu region toward the central Jiangsu and northern Jiangsu regions. Environmental pollution is redistributed among prefecturelevel cities because of intercity industrial transfer; the spatial characteristics of pollution exhibit a notable hierarchical pattern. Furthermore, the transferred pollution load differs considerably between industries. The textile industry and chemical raw material and chemical product industry are mainly transferred toward the Central Jiangsu and Northern Jiangsu regions, whereas the papermaking and paper product manufacturing industry is primarily redistributed to the Southern Jiangsu region. The empirical results can serve as a reference for analyzing the environmental pollution effects of regional industrial transfer.
\end{abstract}

Keywords: industrial transfer; environmental effect; pollution load; case study

\section{Introduction}

Adjustments to the positions of international corporations in the global supply chain have prompted industries to frequently transfer to or cluster in various countries and regions. Since the beginning of the 20th century, four major international industrial transfers have been completed. The first occurred at the start of the 20th century, when England transferred its excessive industrial capacity to the United States. The second in the 1950s, when the United States transferred its traditional industries, such as steel and textile industries, to Japan and Germany. The third occurred in the 1960s and 1970s, when Japan and Germany transferred high-labor-intensity processing industries, such as light industries and textile industries, to the Four Asian Tigers (i.e., South Korea, Taiwan, Hong Kong, and Singapore). In the fourth international industrial transfer, which occurred at the start of the 
21st century, China received industrial transfer of manufacturing industries worldwide. In addition, China moved its low-end manufacturing industries inland or overseas, accelerating the industry's development into high-end industry. Industrial transfer has also induced the transfer of the environmental impact associate with industrial activity. Cross-border industrial transfer primarily consists of direct or indirect interorganizational investment into the host country.

Scholars have discussed whether the environmental stress caused by industrial development during a country's economic growth can be mitigated [1-3]. Studies in which non-Chinese scholars analyze the effects of industrial transfer on environmental quality are few; most have discussed the environmental effects of industrial transfer from a national standpoint [4]. An empirical analysis conducted by Hanif Imran et al. on 15 Asian countries revealed that direct investment from overseas countries is the cause of environmental degradation in host countries [5]. Wang et al. compared the environmental changes in developing versus developed countries during the industrial transfer process and revealed that the $\mathrm{PM}_{2.5}$ levels increased and decreased, respectively, because of the industrial transfer [6]. This result was also obtained by Raza et al. by using monthly statistics for the United States from 1973 to 2015 [7].

As the global community endeavors to create greener environments, discussions on the reduction of $\mathrm{CO}_{2}$ emissions have become inevitable [8]. However, Sapkota and Bastola investigated the environment of the United States and revealed that direct overseas investment in clean energy and energy conservation industries is conducive to reducing environmental pollution [9]. Sarkodie and Strezov analyzed the five countries with the highest greenhouse gas emissions (i.e., China, India, Iran, Indonesia, and South Africa) and discovered that it is easy for the industries with overseas investment to receive the transfer of cleaning technology and the implementation environmental management. This discovery can facilitate the sustainable development in China to a certain extent [10]. Charfeddine and Kahia employed a panel vector autoregressive model to study the environment of 24 countries in the Middle East and Northern Africa; although industrial development and transfer were found to have a positive effect on environmental governance, the effect was minor [11]. However, international industrial transitions may nonlinearly influence the environment of developing countries. This finding is consistent with that of Doytch and Uctum [12], Liang [13], and Wei et al. [14].

Achieving sustainability and improving citizens' health and quality of life are the main objectives of any government [15-17]. Studies have indicated that international industrial transfers have considerably differing environmental effects on different countries. Scholars have focused on the environmental effects of industrial transfer within countries or specific regions. Yoon and Nadvi [18] analyzed the industrial transfer performed by the Korean brand Banwol-Sihwa and revealed that through industry clusters, high ecological collectivism efficiency could be achieved and environmental pollution could be reduced. A study conducted on Latin America indicated that domestic industrial transfer is conducive to improving environmental quality [9]. However, studies on the effect of industrial transfer between Chinese provinces or regions have been inconsistent. Some scholars have posited that industrial transfer is conducive to improving environmental quality. Sun et al. [19] proposed that the transfer of carbon emissions among Chinese industries facilitates the reduction of carbon emissions, thus having positive environmental effects. Wang et al. adopted the country perspective and proposed that under the influence of environmental policies, industrial transfer has had a positive environmental effect [6].

Yang and Li argued that on a provincial level, improving environmental standards reduces the environmental pollution caused by industrial clusters [20]. Wang et al. [21] investigated industrial transfer within the Beijing-Tianjin-Hebei metropolitan area and discovered that under the influence of environmental policies, industrial transfer increased industrial energy consumption efficiency and reduced environmental pollution [22]. However, other scholars have discovered that industrial transfer in China exacerbated environmental pollution in developed regions. Hu et al. investigated the industrial transfer of 
pollution-intensive industries in China between 2007 and 2016, revealing that industrial transfer resulted in pollution transfer [23]. Yin et al. investigated the relationship between economic development and the environment of eight economic regions in China during an industrial transfer process and discovered that industrial transfer increased the environmental stress and pollution levels in the host regions [24]. Scholars researching the effect of industrial transfer of pollution-intensive industries on urban clusters $[25,26]$ and Jiangsu [27] have derived similar conclusions. Furthermore, several scholars have reported that different types of industrial transfer exert varying environmental influences [28], and that industrial transfer under different economic development standards generates differing environmental effects [29-31].

The literature review indicates that Chinese and worldwide scholars have researched the effect of industrial transfer on the environment in various countries and regions, and their findings indicate varying influences of industrial transfer on the environment. In studies on industrial transfer, countries and regions with considerable differences in economic development, industrial structure, and environmental policies have generally been researched. However, studies discussing industrial transfer under these conditions must include discussion on the effect of industrial transfer on the environment. The environmental effects of industrial transfer can be classified into scale, composition, and technology effects [32].

The scale effect refers to decreased environmental quality due to increased industrial production from interregional industrial transfer. The composition effect is defined as a change in environmental quality caused by a change in the industrial structure as a result of industrial transfer. For a fixed total production quantity, regions in which pollution-intensive industries account for a greater proportion of all industry have poorer environmental quality. Finally, the technology effect refers to a change in regional production technology and pollution prevention technology caused by industrial transfer. These changes, under a fixed production value, create differences in environmental quality among regions of environmental transfer. Few studies have investigated the environmental effects of interprovincial or interregional industrial transfer between regions with similar economic development, industry structure, and environmental policies.

Provincial regions with smaller differences in industrial foundation and structure have more consistent government policies on environmental protection and governance. This study does not consider the development of regional industries and instead discusses differences in the industrial transfer for several regions, thereby detailing the transfer of industrial corporations and pollution generation in the industrial transfer process. The study findings are conducive to exploring industrial development conditions and environment policies, identifying patterns and features in regional industrial transfer, and understanding how coordinated regional development enhances environmental effects. The findings will thus be of help when establishing industry transfer policies for sustainable regional development.

In computations of the amount of pollution generated by industrial transfer, the pollution caused by the development of existing industries in the host region should be excluded because such development in each prefecture-level city may have resulted in changes to the amount of pollution generated. When industrial development is conducted under specific conditions, changes in production rate are correlated with changes in production output.

In the present study, the average technology level of each prefecture-level city was set as equal to that of Jiangsu overall. Technology level determines pollution intensity; therefore, the pollution intensity was set as equal to that generated by industrial development in Jiangsu. The industrial transfer is directional, and changes in output value can only show that the pattern of regional industrial development has changed. This is due to the transfer of industries between different regions. This study is conducted under the conditions of an open economy, without considering the impact of foreign capital inflow and the entry of enterprises from other regions. 


\section{Research Region and Model Construction}

\subsection{Research Region}

Industrial environmental pollution endangers civilians' health. Key sources of environmental pollution include the processing, manufacturing, use, and recycling processes of industries. China is the world's largest production and consumption country [33]. Jiangsu, located on the eastern coast of China and downstream of the Yangtze River, is situated in the Yangtze River Economic Zone, which comprises 13 provinces (Figure 1).

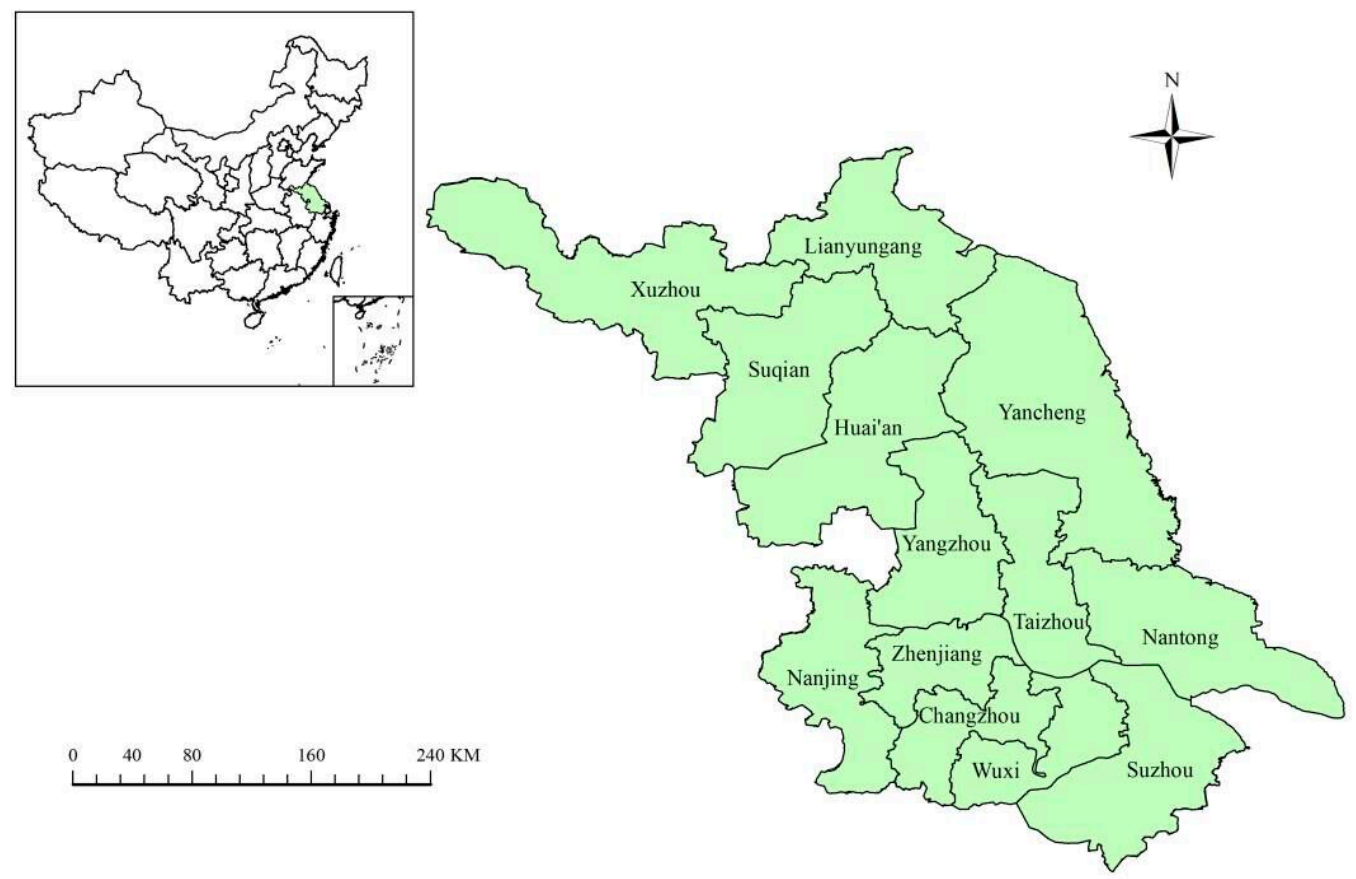

Figure 1. Position of Jiangsu.

Jiangsu has the highest gross domestic production (GDP), comprehensive competitiveness, and development of life index among all provinces in China; it thus has the highest overall development standards and economic activity in the country [34]. In 2019, Jiangsu's GDP was CN¥9.96 trillion, 6.1\% higher than that in 2018. Because of continuous economic structure optimization and the replacement of old growth drivers with new ones, Jiangsu's secondary industry exhibited $5.9 \%$ growth in 2019 . The province's electronics, medicine, computation, and instrumentation industries exhibited $69.0 \%, 33.8 \%, 23.7 \%$, and $79.5 \%$ growth, respectively.

Jiangsu's high-tech industry exhibited $6.8 \%$ growth in 2019 , which was $0.6 \%$ higher than the growth rate of industries above the designated size and contributed to the growth of the added value of such industries by $23.8 \%$. In particular, strategic emerging industries and high-tech industries comprised $32.8 \%$ and $44.4 \%$ of the above-designated size industries, respectively, and are thus suitable as a basis for analyzing high-quality development.

Regarding disadvantages, Jiangsu has a shortage of natural resources and depends on input of coal, oil, natural gas, and water. Jiangsu's well-developed water network primarily consists of cross-border water resources; therefore, the province has a shortage of high-quality water. In 2018, the water demand per capita was $470.6 \mathrm{~m}^{3}, 1971.7 \mathrm{~m}^{3}$ less than the national average. In 2018, Jiangsu's total water pollution emissions, 5.839 billion tons, were the second highest nationwide. Relative to the recorded water pollution emissions in 2017, this was $1.51 \%$ growth. Therefore, given its high-quality economic development, determining how Jiangsu can continue to optimize its economic structure and replace its old growth drivers with new ones to enhance the ecological environment is crucial, particularly in relation to enhancing water-related environment quality. 
The researchers selected Jiangsu as the research target for three reasons: (1) Jiangsu has a shortage of water resources; (2) industry in southern Jiangsu and northern Jiangsu is currently in a state of transition and optimization; (3) the economic development, environmental regulations, and external environment of the province are consistent across the province. By using Jiangsu as the research target, the researchers could more effectively quantify the environmental effect of industrial transfer in the high-quality economic development process and devise more effective responses for addressing environmental quality changes caused by high-quality economic development.

\subsection{Subsection}

In this study, the measurement model quotes He, Zhou and Zhang industrial transfer and its environmental effect for empirical analysis [4].

Regarding notation, the previous year represents the baseline, and $\gamma_{t-1, i j}$ and $\gamma_{t, i j}$ denote the industrial production value of industry $j$ in prefecture-level city $i$ at time points $t-1$ and $t$, respectively. The industrial growth rate of each prefecture-level city is set as equal to that of Jiangsu, thus $\gamma(0)_{t_{1} i j}=\dot{\gamma}_{t j}(0$ represents the hypothetical situation before the matrix conversion and "." represents the growth rate). Accordingly, the production value is calculated using $\gamma(0)_{t, i j}=\gamma_{t-1, i j} \cdot\left(1+\dot{\gamma}_{t j}\right)$. Therefore, the total production value of prefecture-level city $i$ during period $t$ when industrial transfer does not occur is $\gamma(0)_{t, i}=\sum_{j} \gamma(0)_{t, i j}$. The pollution intensity of industry $j$ during period $t$ is equal to the ratio of the amount of pollution generated to the total industrial production value, which is represented as $\tau_{t, j}=P_{t, j} / \gamma_{t, j}$. In the equation, $P_{t, j}$ represents the amount of pollution generated by industry $j$ in period $t$. Pollution intensity is determined by technology level; the pollution intensity of each city is set as equal to that of the industries in Jiangsu. Therefore, the amount of pollution generated by industry $j$ of prefecture-level city $i$ during period $t-1$ is $\tau_{t-1, j} \cdot \gamma_{t-1, i j}$; the pollution generated by industry $j$ of prefecture-level city $i$ during period $t$ when industrial transfer does not occur is $\tau_{t, j} \cdot \gamma(0)_{t, i j}$.

Accordingly, the change in the amount of pollution generated in prefecture-level city $i$ when industrial transfer does not occur is calculated using

$$
\Delta P(0)_{t, i}=\sum_{j} \tau_{t, j} \cdot \gamma(0)_{t, i j}-\sum_{j}\left(\tau_{t-1, j} \cdot \gamma_{t-1, i j}\right)
$$

This study referenced the environmental factor decomposition model of Grossman [32] to decompose Equation (1) into the following:

$$
\begin{gathered}
\Delta P(0)_{t, i} \approx( \\
\left.(0)_{t, i}-\gamma_{t-1, i}\right) \sum_{j} \tau_{t, j} \cdot \frac{\gamma(0)_{t, i j}}{\gamma(0)_{t_{1} i}}+\gamma(0)_{t, i} \cdot \sum_{j} \tau_{t, j} \cdot\left(\frac{\gamma(0)_{t, i j}}{\gamma(0)_{t, i}}-\frac{\gamma_{t-1, i j}}{\gamma_{t-1, i}}\right) \\
+\gamma(0)_{t, i} \sum_{j}\left(\tau_{t, j}-\tau_{t-1, j}\right) \cdot \frac{\gamma(0)_{t, i j}}{\gamma(0)_{t, i}}=\Delta P(0)_{s}+\Delta P(0)_{c}+\Delta P(0)_{t}
\end{gathered}
$$

By using Equation (2), the scale, composition, and technology effects of industrial growth on the environment can be quantified. The effect of each factor is represented by the scale, composition, and technology coefficients $\Delta P(0)_{s} / \Delta P(0), \Delta P(0)_{c} / \Delta P(0)$, and $\Delta P(0)_{t} / \Delta P(0)$, respectively.

After excluding foreign investment, the production generated by industrial transfer is computed by deducting the actual production value of each industry in each prefecturelevel city by the corresponding theoretical production value when industrial transfer does not occur. Therefore, $v_{t, i j}$ represents the amount of production generated by industrial transfer in industry $j$ of city $i$ from period $t-1$ to $t$, computed as follows:

$$
v_{t, i j}=\gamma_{t, i j}-\gamma(0)_{t, i j}=\gamma_{t, i j}-\gamma_{t-1, i j}-\gamma_{t-1, i j} \dot{\gamma}_{t, j}
$$

When $v<0$ and $v>0$, prefecture-level city $i$ transfers out and in $j$ industries, respectively. The number of industries transferred in and out of prefecture-level city $i$ during 
period $t$ is represented as $I_{t, i}=\sum_{j} v_{i j}\left(v_{i j}>0\right)$ and $E_{t, i}=\sum_{j}\left|v_{i j}\right|\left(v_{i j}<0\right)$, respectively; $v_{t, i j}$ is computed as follows:

$$
\begin{aligned}
v_{t, i j} & =\gamma_{t, i j}-\gamma(0)_{t, i j}=\sum_{i} \gamma_{t, i j} \frac{\left(\gamma_{t, i j}-\gamma(0)_{t, i j}\right)}{\sum_{i} \gamma_{t, i j}}=\sum_{i} \gamma_{t, i j}\left(\frac{\gamma_{t, i j}}{\sum_{i} \gamma_{t, i j}}-\frac{\gamma_{t-1, i j} \cdot\left(1+\dot{\gamma}_{t, j}\right)}{\sum_{i} \gamma_{t, i j}}\right) \\
& =\sum_{i} \gamma_{t, i j} \cdot\left(\frac{\gamma_{t, i j}}{\sum_{i} \gamma_{t, i j}}-\frac{\gamma_{t-1, i j} \cdot\left(1+\dot{\gamma}_{t, j}\right)}{\left(\sum_{i} \gamma_{t-1, i j}\right) \cdot\left(1+\dot{\gamma}_{t, j}\right)}\right)=\sum_{i} \gamma_{t, i j} \cdot\left(\frac{\gamma_{t, i j}}{\sum_{i} \gamma_{t, i j}}-\frac{\gamma_{t-1, i j}}{\left(\sum_{i} \gamma_{t-1, i j}\right)}\right)
\end{aligned}
$$

The net industry transfer is represented as $v_{t, i}=\sum_{j} v_{i j}$. Accordingly, the number of transferred industries $j$ in prefecture-level city $i$ is equal to the difference in the share of industry $j$ in prefecture-level city $i$ in the province before and after the transfer multiplied by the total production value of industry $j$ after the transfer was completed. The baseline condition of prefecture-level city $i$ before the industrial transfer in the current year is determined by the industrial structure of said city after the industrial transfer in the previous year. The computed result is equal to the industrial transfer result computed using the relative market share formula.

Therefore, the amount of pollution transfer of industry $j$ in prefecture-level city $i$ during period $t$ is computed using $\rho_{t, i j}=v_{t, i j} \cdot \tau_{t, j}$, in which $\tau_{t, j}$ represents the pollution intensity of industry $j$ in period $t$ and $v_{t, i j}$ represents the total pollution generated by industrial transfer. Therefore, the amount of pollution transfer caused by industrial transfer in prefecture-level city $i$ during period $t$ is $\Delta P(\text { ind fix })_{t, i}=\sum_{j} \rho_{t, i j}$.

The total amount of pollution generated due to industrial transfer, calculated using the number of transferred industries, is

$$
\Delta P(\text { indfix, im })_{t, i}=\sum_{j} v_{t, i j} \cdot \tau_{t, j},\left(v_{i j}>0\right)=I_{t_{1} i}\left(\sum_{j} \frac{v_{t, i j}}{I_{t, i}} \cdot \tau_{t, j}\right)=I_{t, i} \cdot A I_{t, i}\left(v_{i j}>0\right)
$$

The total pollution generated is calculated using the following equation:

$$
\Delta P(\text { indfix }, \text { em })_{t, i}=\sum_{j}\left|v_{t, i j}\right| \cdot \tau_{t, j}\left(v_{t, i j}<0\right)=E_{t, i}\left(\sum_{j} \frac{v_{t, i j}}{E_{t, i}} \cdot \tau_{t, j}\right)=E_{t, i} \cdot A E_{t, i}\left(v_{i j}<0\right)
$$

where $I_{t, i}$ and $E_{t, i}$ represent the GDP generated by industrial transfer in and out of prefecture-level city $i$, respectively, and $A I_{t, i}$ and $A E_{t, i}$ represent the pollution coefficient generated by industrial transfer in and out, respectively. Accordingly, the total pollution transfer of city $i$ is $\sum_{t} \Delta P(\text { indfix })_{t, i}=\sum_{t} \sum_{j} \rho_{t, i j}$, in which the total import and export pollution are $\sum_{t} \Delta P(\text { ind fix, im })_{t, i}$ and $\sum_{t} \Delta P(\text { ind fix, em })_{t, i}$, respectively.

After industrial transfer, the change in the amount of pollution generated by prefecturelevel city $i$ is calculated as follows:

$$
\sum_{t} \Delta P(\operatorname{tran})_{t, i}=P_{t, i}-P_{t-1, i}-\Delta P(0)_{t, i}
$$

Equation (7) represents the amount of pollution generated by prefecture-level city $i$ after subtracting the amount of pollution generated by the industrial development of pre-existing industries. $\Delta P(0)$ represents the environmental effect of pre-existing industries due to their growth. In theory, $\Delta P(\text { indefix })_{t, i}=\Delta P(\text { tran })_{t, i}$.

\subsection{Data Source and Processing}

The data in this study is collected from the Statistical Yearbook of Jiangsu and the relevant yearbooks of Nanjing, Suzhou, Wuxi, Changzhou, Nantong, Taizhou, Yangzhou, Zhenjiang, Yancheng, Xuzhou, Huaian, Lianyungang, and Suqian. The industrial enterprise data is consisted of only the data on industries above the designed size; statistical indices included the prefecture-level city of each industry, industrial output value, industrial wastewater emission (ten thousand tons), and industry category. Because direct foreign investment in the analyzed industries increased annually, the effect of direct foreign investment was not considered in the analysis. Because of differences in industry classifi- 
cation standards, this study selected industry classification statistics from the Statistical Yearbook of Jiangsu between 2006 and 2018 for analysis.

Taking into account that the cost of carbon emissions to environmental pollution is not limited to Jiangsu Province, it will further spread to East Asia and the world. Water environmental pollution has significant regional characteristics, and under strict water quality monitoring, the cost of water pollution control is mainly determined by the enterprises commitment which can better reflect who is responsible for water pollution. Therefore, the environmental pollution in this article mainly refers to the discharge of industrial wastewater.

\section{Industrial Composition Changes and Pollution Transfer in Jiangsu}

\subsection{Status of Industrial Transfer in Jiangsu}

At the time of writing, a consensus had not yet been reached among scholars regarding the definition of industrial transfer. However, most scholars have defined industrial transfer as the spatial transfer or movement of a certain industry. Accordingly, this study defined industrial transfer in Jiangsu to be the growth of each prefecture-level city minus the estimated growth if industrial transfer were to not have occurred.

\subsection{Spatial Characteristics of Industrial Transfer in Jiangsu}

To comprehensively analyze the overall trend in industrial transfer in Jiangsu's prefecture-level cities during the research period, this study computed the number of total transferred-in industries $\left(\sum_{t} I_{t, i}\right)$ and transferred-out industries $\left(\sum_{t} E_{t, i}\right)$; the results are illustrated in Figure 2. Among the prefecture-level cities in Jiangsu between 2006 and 2018, industries mainly transferred out of Suzhou, Wuxi, and Nanjing and transferred to Xuzhou, Taizhou, and Huaian.

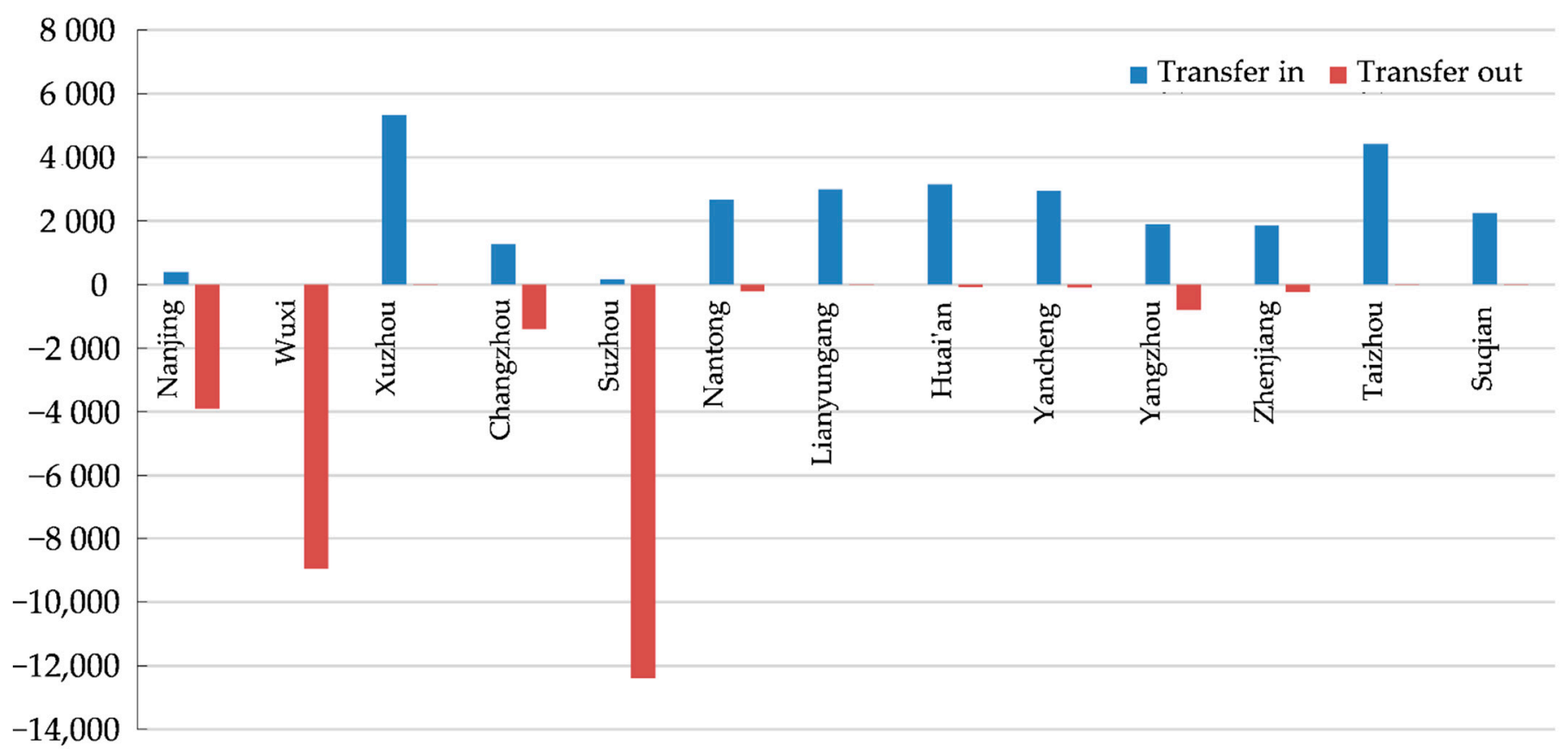

Figure 2. Amount of transfer in and transfer out between 2006 and 2018 for each prefecture-level city in Jiangsu (CN¥100 million). Source: Authors calculation based on the Statistical Yearbook of Jiangsu (2007-2019).

The data on Jiangsu indicated that in prominent prefecture-level cities in Southern Jiangsu such as Suzhou, Wuxi, and Changzhou, the transfer out of industry was the main method of optimizing and upgrading the industry structure, and the number of transfers in was notably lower than that of transfers out. By contrast, in prefecture-level cities in central Jiangsu and Northern Jiangsu — such as Taizhou, Xuzhou, and Huaian- 
the number of industries transferred in far exceeded that of industries transferred out. Most prefecture-level cities with notable changes in industrial structure had more active industrial transfer, such as Yangzhou, Changzhou, Nanjing, Zhenjiang, and Nantong. However, Wuxi was unique because it had few transferred-in industries; additionally, the number of transferred-out industries in Suqian, Lianyungang, and Taizhou was low.

\subsection{Characteristics of Transferred Industries}

Theories on industrial transfer have assumed that the direction of industrial transfer is from economic centers to the periphery and outer regions. Additionally, transferred industries can be categorized as resource- and labor-intensive industries or capital- and technology-intensive industries. Further details on the transferred-in and transferred-out industries are provided in the following. Appendix A analyzes four prefecture-level cities with unique industrial transfer characteristics, namely Nanjing, Changzhou, Suzhou, and Nantong.

Transferred-out industries in Nanjing were mostly those using mature production technology. The chemical raw material, metallurgical, and petroleum processing industries accounted for large shares of Jiangsu's industrial structure. In particular, the chemical material, nonferrous metal ore mining, petrochemical, and food manufacturing industries generated severe pollution [4,17]. The total number and types of transferred-out industries exceeded those of transferred-in industries. The main transferred-in industry was that producing instruments, meters, and cultural and clerical machinery products, which fulfils the requirements for economic culture activities in prefecture-level cities [18].

In Changzhou, more industries were transferred out than in. The city's transferred-in industries - other than those manufacturing articles for culture, education, and sport activities; papermaking and paper products; leather, fur, and feather products; food productswere heavy industries such as those manufacturing electrical machinery and equipment, smelting and pressing ferrous metals, manufacturing chemical materials, and processing petroleum. The chemical raw material and ferrous metal smelting and pressing industries have high pollution intensity. The transferred-out industry were the textile, rubber, and plastic product industries and heavy industries in which severe environmental pollution is generated, such as those manufacturing general and special purpose machinery and smelting and pressing nonferrous metals.

Far fewer industries were transferred in than out. Those transferred out were primarily heavy industries that generate severe pollution. However, the transfer-in and transferout conditions of Nantong were discovered to differ from those of Jiangsu overall; fewer industries were transferred out of industries in Nantong than transferred in, and most of the transferred-in industries were heavy industries.

\section{Discussion}

\subsection{Differences in Spatial Pattern of Pollution Emissions Caused by Industrial Transfer}

Each prefectural-level city has a different industrial structure and industrial growth rate, and the pollution emission intensity of each industry is different. Therefore, to determine the spatial pattern characteristics of pollution emissions caused by industrial transfer, the researchers investigated the environmental effects caused by industrial growth in each industry category. Figures 3 and 4 depict the total industrial wastewater emission and pollution intensity for key industries in 2006, 2012, and 2018.

Figure 3 indicates that differences existed in the pollution emissions of each industry during the research period. In particular, the pollution emissions of the chemical raw material, electric power and heat power production and supply, paper manufacturing, petroleum processing, medicine manufacturing, food manufacturing, and nonferrous metal smelting and pressing industries decreased over the entire period. However, the pollution emissions of the beverage manufacturing, coal mining, metal product manufacturing, and agricultural product food processing industries increased. 


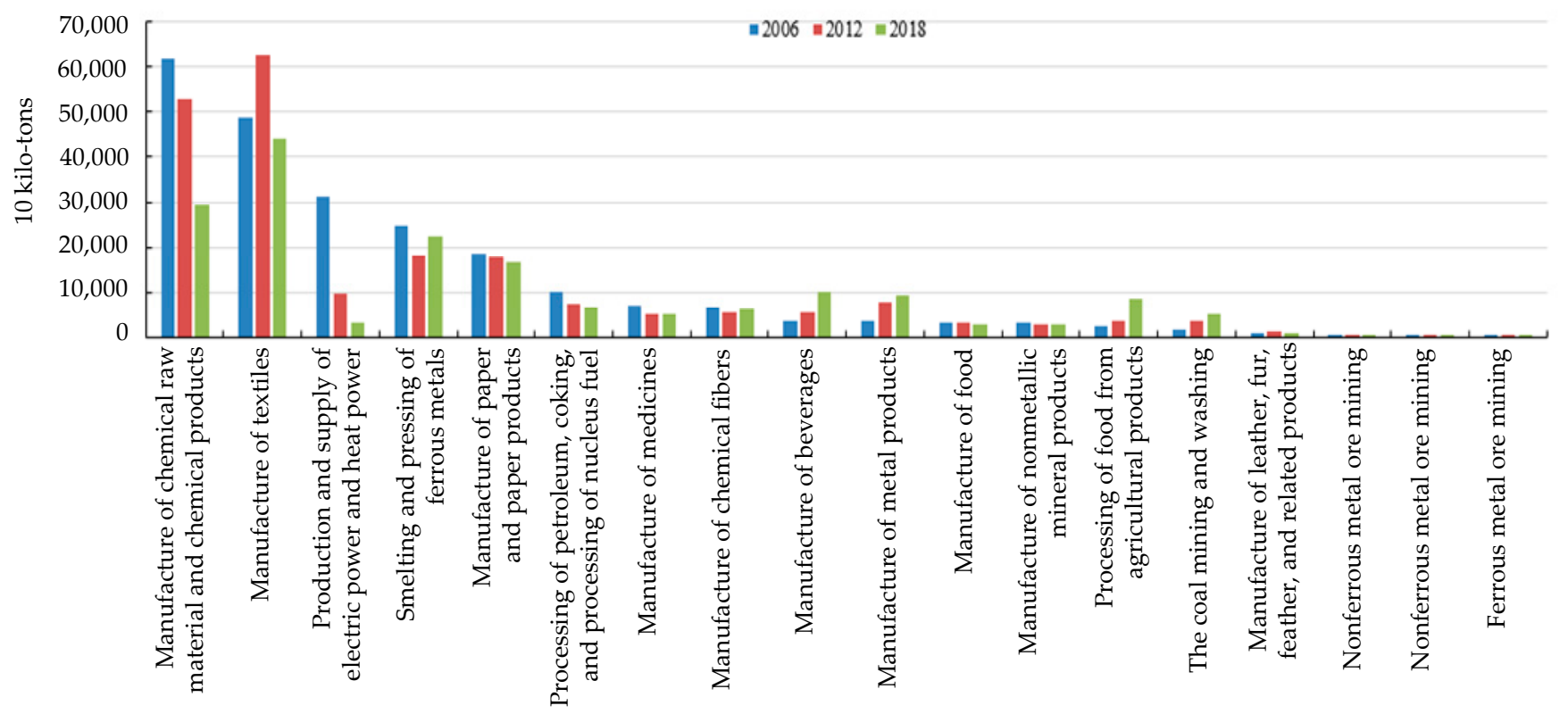

Figure 3. Pollution emissions of key industries in 2006, 2012, and 2018 (industrial wastewater). Source: Authors calculation based on the Statistical Yearbook of Jiangsu (2007, 2013, and 2019).

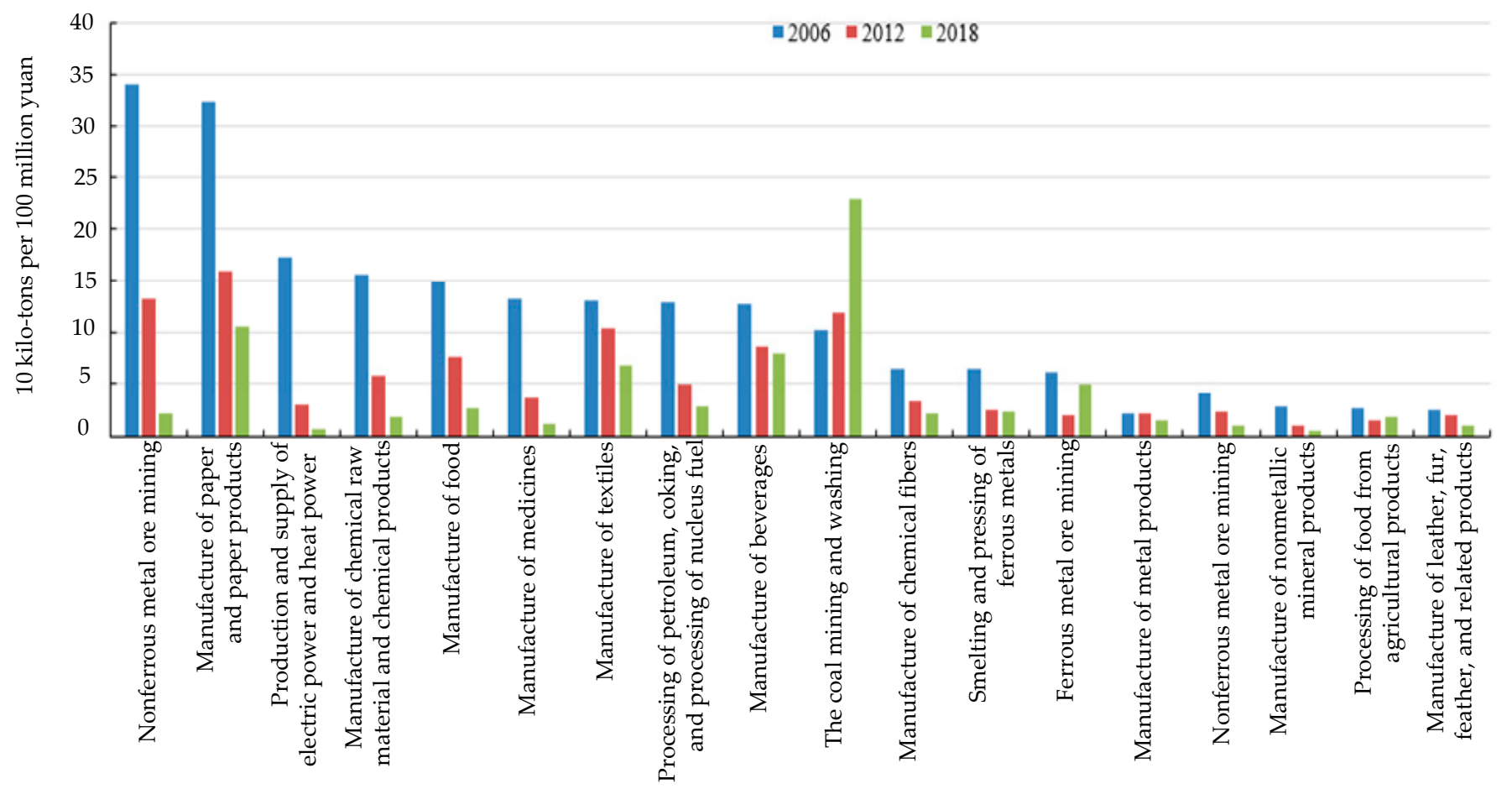

Figure 4. Pollution intensity of key pollution industries in 2006, 2012, and 2018 (industrial wastewater). Source: Authors calculation based on the Statistical Yearbook of Jiangsu (2007, 2013, and 2019).

The pollution emissions of the textile; leather, fur, feather, and related product; and nonferrous metal smelting and pressing industries increased between 2006 and 2012 but then decreased between 2012 and 2018. The pollution emissions of the chemical fiber manufacturing, nonmetallic mineral product manufacturing, and ferrous metal smelting and pressing industries also had a turning point in 2012. However, the pollution emissions of these three industries decreased between 2006 and 2012 but then increased between 2012 and 2018. 
Figure 4 depicts the pollution intensity for each industry in 2006, 2012, and 2018. The pollution intensity of all industries other than the coal mining and washing, ferrous metal ore mining, and agricultural product processing industries decreased within the research period. The computed pollution intensity indicated that the nonferrous metal ore mining, paper manufacturing, electric power and heat power production and supply, chemical raw material manufacturing, food manufacturing, medicine manufacturing, and textile industries had the highest pollution intensity.

In 2006, the wastewater produced by the chemical raw material and chemical product manufacturing industry was 617.7972 metric tons, $24 \%$ of the total industrial wastewater of Jiangsu. In addition, the textile, electrical power and heat power production and supply, ferrous metal smelting and pressing, and paper manufacturing industries produced considerable industrial wastewater. The combined wastewater of these seven industries and the chemical raw material and chemical product manufacturing industry constituted more than $80 \%$ of the industrial wastewater produced in Jiangsu.

The difference in the environmental effect caused by industrial growth was divided into industrial scale, structure, and differences in pollution intensity. By hypothesizing that technological development within Jiangsu did not vary spatially, the spatial differences in pollution intensity and pollution emissions could be ignored.

Because environmental pollution increases with production, when the production conditions and industrial structure are set, an increase in production results in increased pollution. Therefore, the difference in the spatial distribution of environmental effects caused by industrial growth would be influenced by differences in the industrial structure of the city as well as the industrial structure of the city at baseline.

Using 2018 as an example, and the aforementioned method for computation, Figure 5 illustrates the environmental effect $\Delta P(0)_{t_{1} i}$ caused by industrial growth between 2015 and 2018 in each city. The ratio of environmental effect with structural component coefficient was $\Delta P(0)_{s} / \Delta P(0)_{t_{1} i}$.

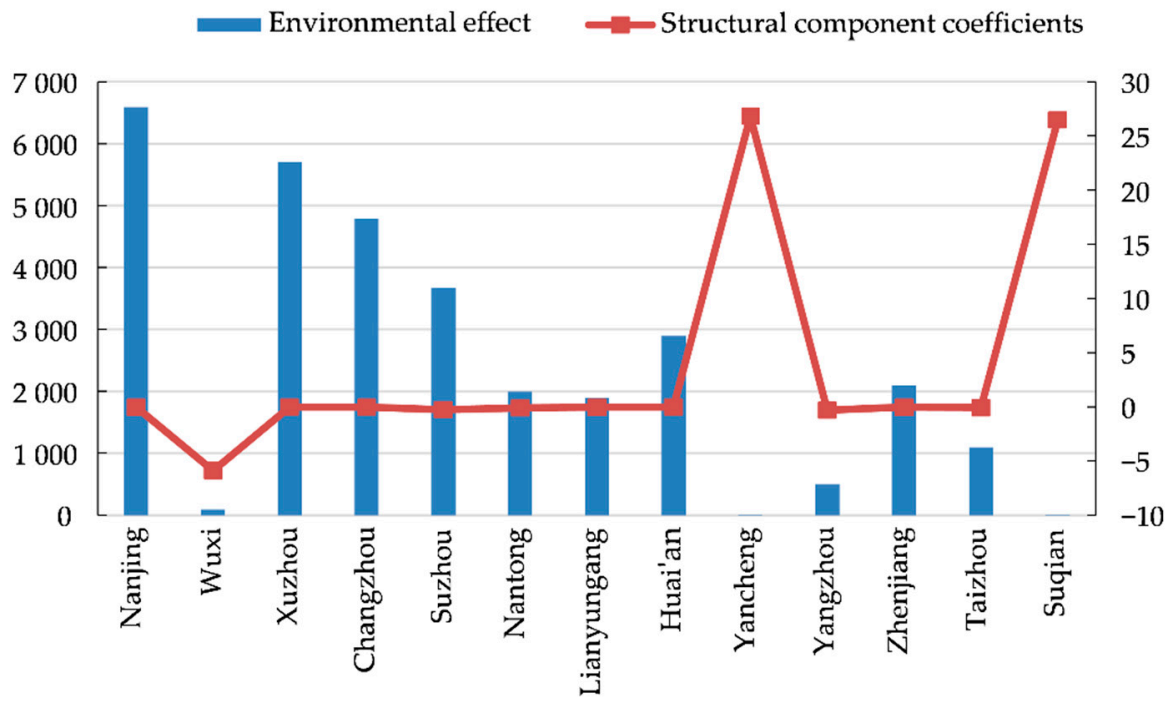

Figure 5. Environmental effect and structural component coefficients attributable to the industrial growth for each prefecture-level city between 2015 and 2018. Source: Authors calculation based on the Statistical Yearbook of Nanjing, Suzhou, Wuxi, Changzhou, Nantong, Taizhou, Yangzhou, Zhenjiang, Yancheng, Xuzhou, Huaian, Lianyungang, and Suqian (between 2016 and 2019).

The size of the environmental effect was closely related to the overall economic development and industrial structure of each prefecture-level city. Xuzhou, Nanjing, and Suzhou were the cities with the highest GDP in Jiangsu; combined, they generated 86.88 million tons of industrial wastewater due to industrial growth. Zhenjiang, Huaian, Yancheng, and Yangzhou also had considerable wastewater emissions due to industrial growth; these 
prefecture-level cities had notably high GDP, which was strongly influenced by the proportion of highly polluting industries in their industrial structure. For the prefecture-level cities that had an increase in GDP, a component coefficient $\left[\Delta P(0)_{s} / \Delta P(0)_{t_{1} i}\right]$ higher and lower than 0 indicated that the city's industrial structure had a negative and positive effect, respectively, on the environment. Between 2015 and 2017, most prefecture-level cities had a negative component coefficient; only Wuxi and Nantong had a positive component coefficient. Thus, the prefecture-level cities having more industries with greater pollution intensity exhibited faster growth.

\subsection{Differences in Spatial Characteristics of Pollution Emissions Caused by Industrial Transfer}

To analyze the total pollution transfer during the research period, the amounts of pollution transferred in $\left[\sum_{t} \Delta P(\text { ind fix, im })_{t_{1} i}\right]$ and out $\left[\sum_{t} \Delta P(\text { ind fix, em })_{t_{1} i}\right]$ between 2006 and 2018 was calculated. However, because various industries were inspected and the pollution intensity of each industry varied, this study collected pollution transfer statistics for industries above the designed size in each region between 2006 and 2018.

Figure 6 indicates that among Jiangsu's prefecture-level cities, Suzhou, Wuxi, Nanjing, and Changzhou had the highest amount of transferred-out pollution. Most of these cities are prosperous and have undergone notable changes to their industrial structure.

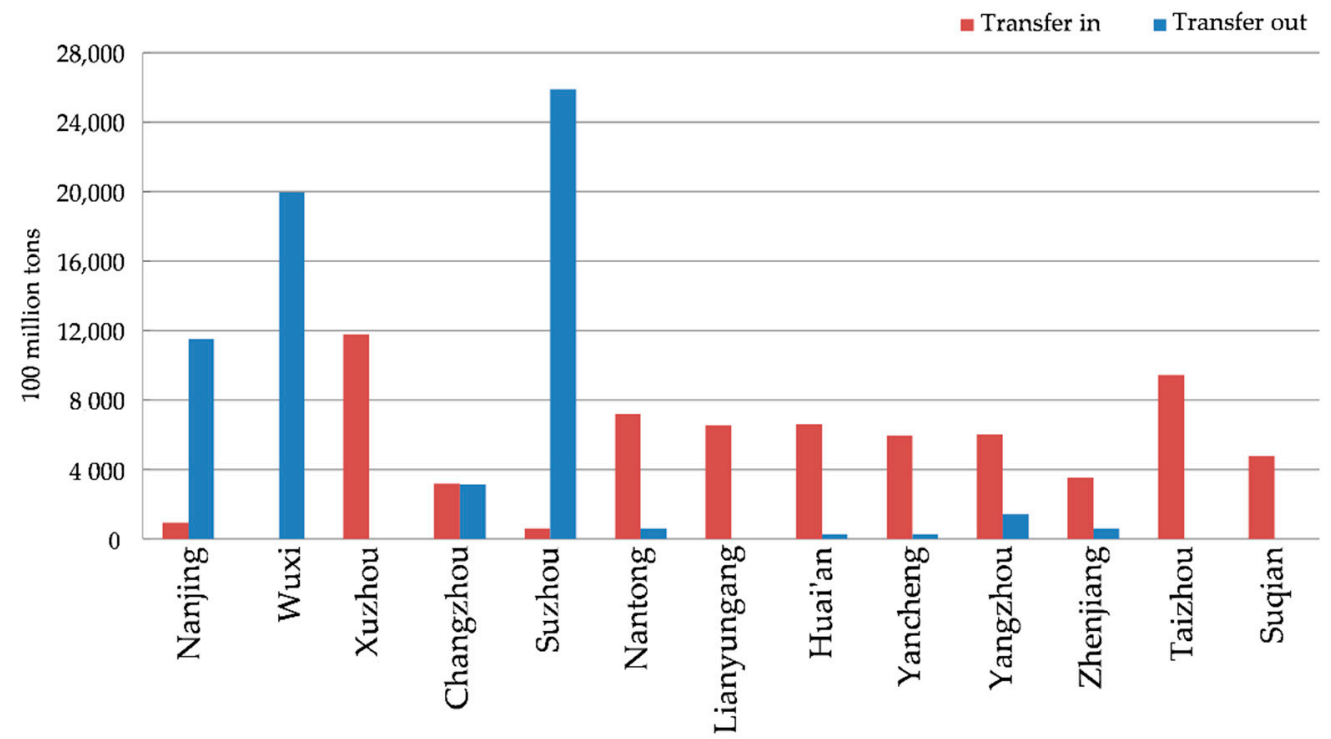

Figure 6. Pollution transfer caused by industrial transfer for each prefecture-level city between 2006 and 2018. Source: Authors calculation based on the Statistical Yearbook of Jiangsu (between 2007 and 2019).

Cities with high levels of transferred-in pollution were Xuzhou, Taizhou, Nantong, Lianyungang, and Yangzhou. Since implementation of the reform and opening-up policy, heavy industries have remained the main component of industry in Xuzhou. As a key province for the transfer in of industry, Xuzhou has adjusted its industrial structure and attracted various highly polluting industries, namely the wood manufacturing, chemical raw material, textile, nonmetallic processing, ferrous metal smelting and processing, and instrumentation manufacturing industries. Because Xuzhou, Lianyungang, Yancheng, and Suqian have been the recipients of industrial transfer in the Jiangnan region, the transferred-in industries of these cities had high pollution emissions.

Overall, in prefecture-level cities such as Nanjing, Wuxi, and Suzhou, the transferredin pollution load was notably lower than the transferred-out pollution load. This indicated that the industrial structure of these cities underwent a greater change.

Figure 7 presents the net transfer of pollution generated for each city, which was computed by subtracting the transferred-in pollution load from the transferred-out pollu- 
tion load. The spatial characteristics of pollution transfer were revealed to be hierarchical. In the first level, prefecture-level cities in Southern Jiangsu — such as Suzhou, Wuxi, and Nanjing - exhibited a net transfer out of pollution load, indicating that in these cities, less pollution load was transferred in than out. In the second level, prefecture-level cities in Central Jiangsu and Northern Jiangsu — such as Taizhou, Xuzhou, and Yancheng-had a net transfer in of pollution load. Comparing the industrial transfer characteristics of cites in the two levels revealed that those in the second level had relatively less industrial transfer than those in the first level.

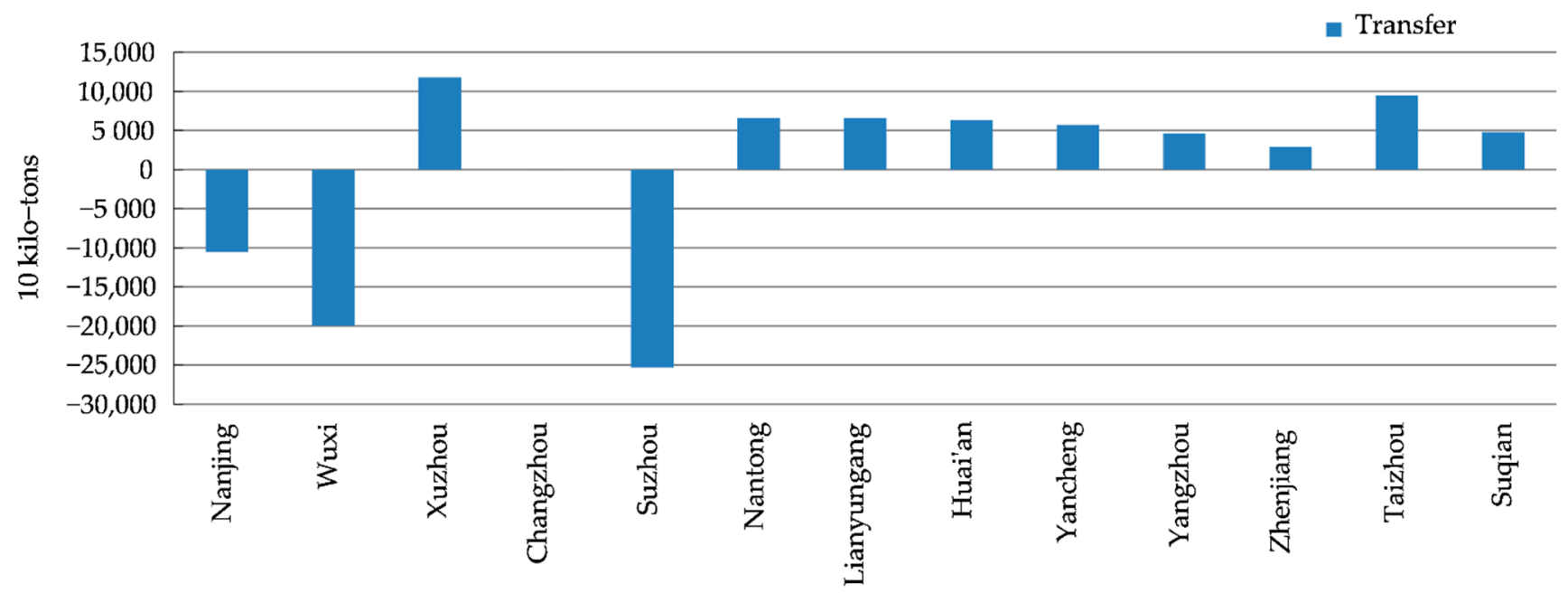

Figure 7. Net transfer of pollution generated for each prefecture-level city between 2006 and 2018. Source: Authors calculation based on the Statistical Yearbook of Jiangsu (between 2007 and 2019).

\subsection{Differences in Pollution Load Caused by Industrial Transfer}

Different industries have differing pollution intensity. This study specifically analyzed the highly polluting industries, namely the textile, papermaking and paper product manufacturing, and chemical raw material and chemical product manufacturing industries. However, because of limitations in the collected data, only data on the pollution transfer conditions of each industry between 2011 and 2018 were included.

The textile industry is the traditional major industry of Jiangsu and a major source of pollution of the province's water bodies. Figure 8 indicates that pollution was mainly transferred out of Suzhou, Nanjing, Wuxi, and Suqian and transferred into Xuzhou, Yancheng, and Huaian. The change in the industrial structure of each prefecture-level city was observed from pollution transfer conditions. For example, a considerable portion of Suzhou's pollution-intensive industries was transferred out to Southern Jiangsu, which now has a cluster of various pollution-intensive industries due to its advantageous geographic conditions. However, because of rapid economic development in the region, pollution problems have increased residents' awareness of industrial pollution risks and knowledge of environmental protection. Furthermore, government agencies have endeavored to establish and implement environmental protection policies. By actively implementing policies to change its industrial structure, Suzhou has prompted pollution-intensive industries to transfer out or shut down. The textile industry is also a pollution-intensive industry that should transfer out. 


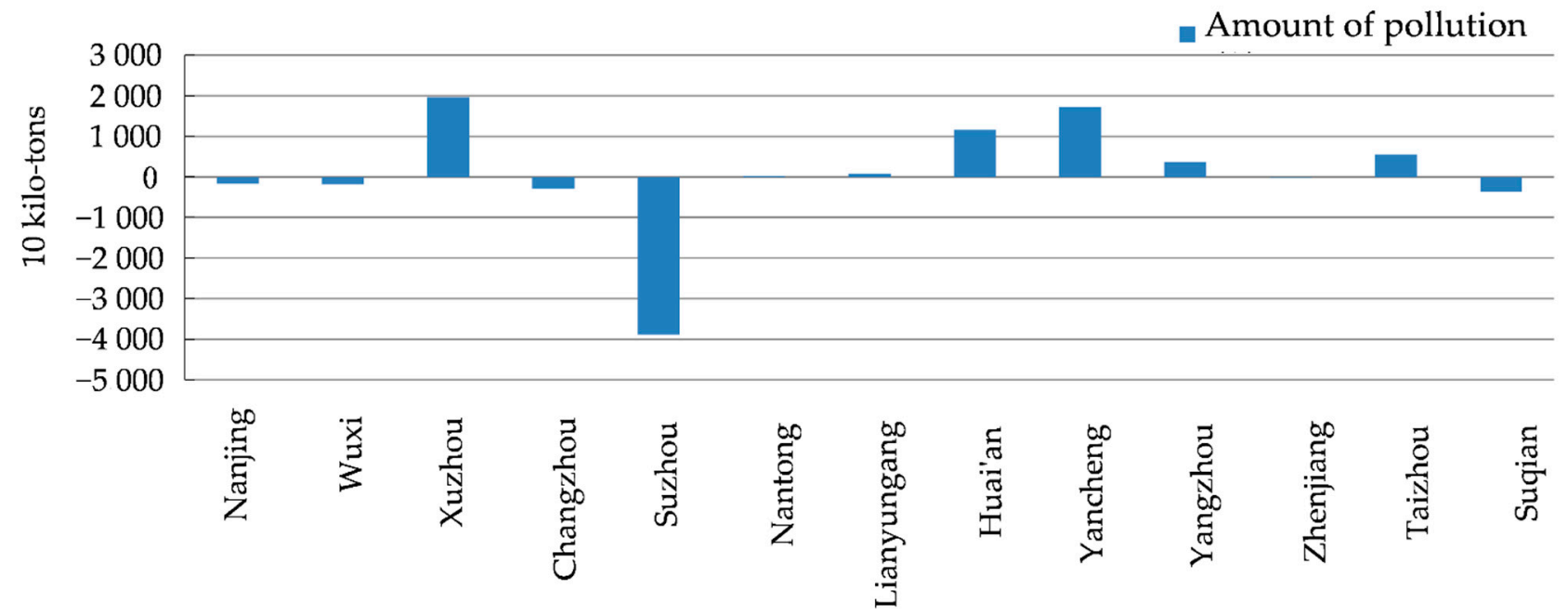

Figure 8. Pollution transfer for the textile industry in each prefecture-level city between 2011 and 2018. Source: Authors calculation based on the Statistical Yearbook of Nanjing, Suzhou, Wuxi, Changzhou, Nantong, Taizhou, Yangzhou, Zhenjiang, Yancheng, Xuzhou, Huaian, Lianyungang, and Suqian (between 2012 and 2019).

The papermaking and paper product manufacturing industry is representative of pollution-intensive light industries. Figure 9 shows that the pollution generated by this industry was primarily transferred out from Wuxi, Suzhou, and Nanjing and transferred in to Huaian, Changzhou, Nantong, Yancheng, and Yangzhou. In particular, Huaian had the greatest amount of transferred-in pollution for the papermaking and paper product manufacturing industry. From the provincial standpoint, the transferred-in pollution of the papermaking and paper production manufacturing industry considerably exceeded the industry's transferred-out pollution. In addition, a transfer in of pollution was observed in some cities in Southern Jiangsu.

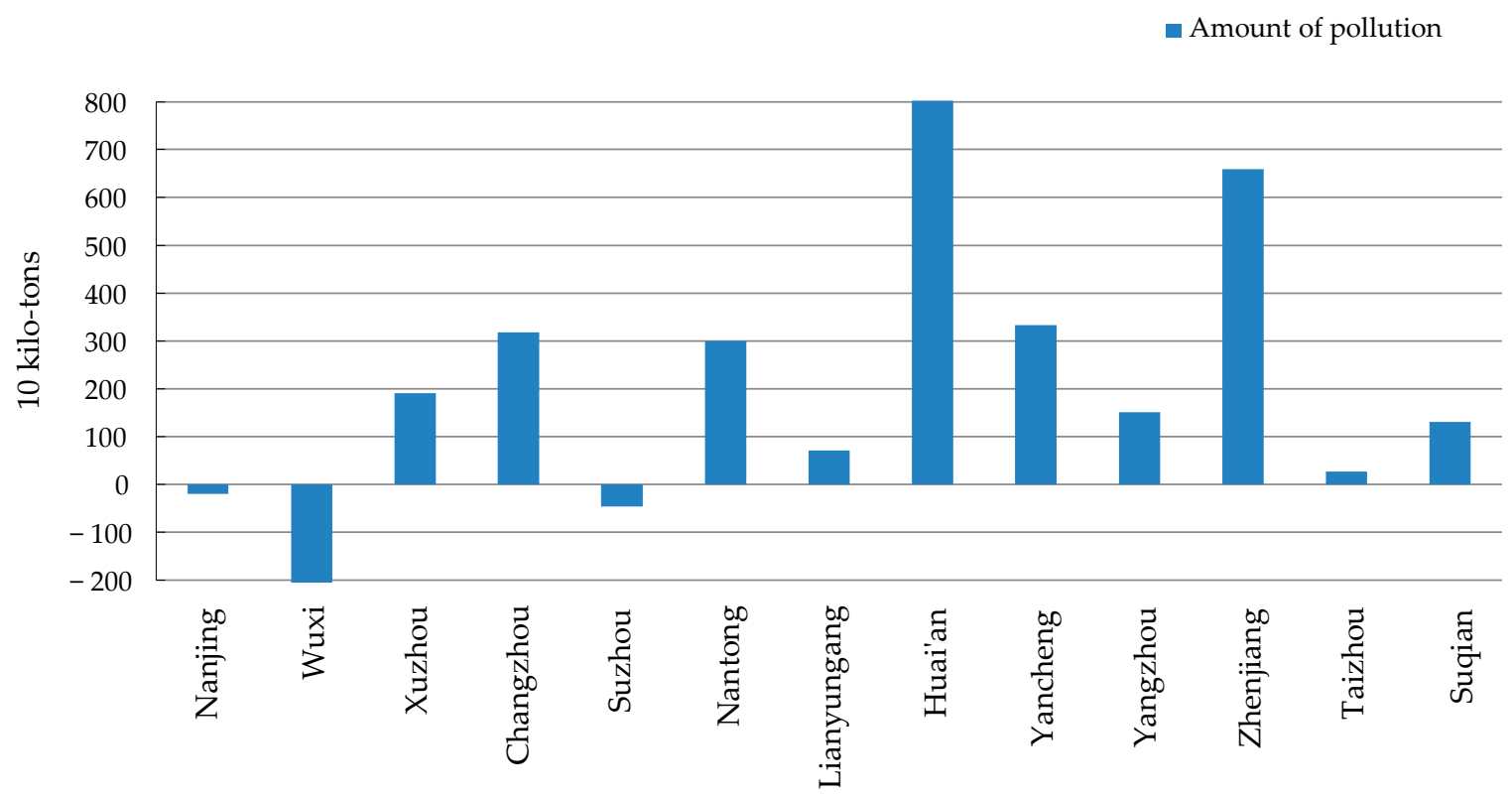

Figure 9. Pollution transfer for the papermaking and paper product manufacturing industry in each prefecture-level city between 2011 and 2018. Source: Authors calculation based on the Statistical Yearbook of Nanjing, Suzhou, Wuxi, Changzhou, Nantong, Taizhou, Yangzhou, Zhenjiang, Yancheng, Xuzhou, Huaian, Lianyungang, and Suqian (between 2012 and 2019 ).

The trend in pollution generated by the chemical raw material and chemical product manufacturing industry was similar to that for the papermaking and paper product manufacturing industry. Figure 10 shows the pollution load of the chemical raw material 
and chemical product industry in Nanjing, Suzhou, Wuxi, and Yangzhou, indicating that the pollution was transferred out because of the transfer out of that industry. Once a main energy production city in China, Xuzhou has more than 100 years of coal mining history, which propelled the development of Xuzhou's classic heavy industry industrial layout and prompted the city to develop into a major traditional industrial city in Jiangsu. The constantly changing proportions of the textile, machinery, and chemical industries in the industrial structure reflect the considerable number of pollution-intensive industries that have transferred into Xuzhou. The transfers in from the textile and chemical raw material industries were particularly prominent, bringing considerable pollution as well as economic development.

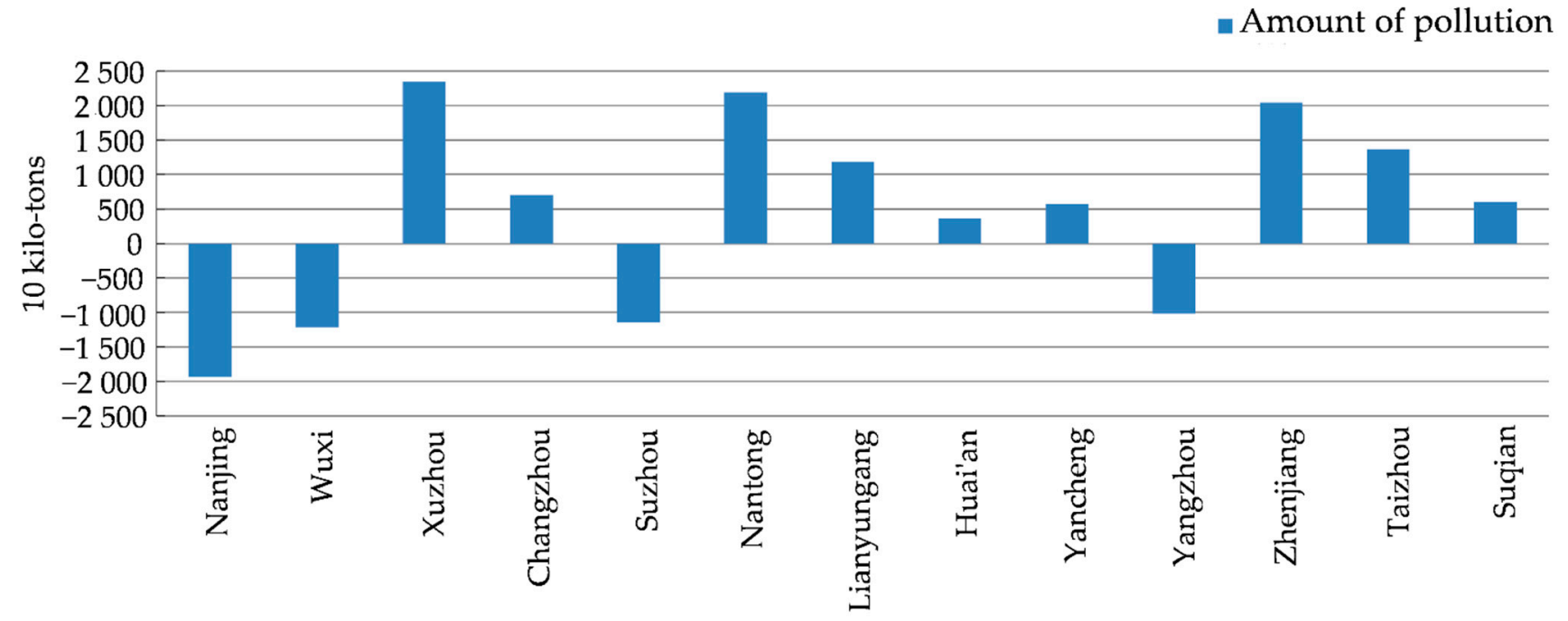

Figure 10. Pollution transfer for the chemical raw material and chemical product manufacturing industry in each prefecturelevel city between 2011 and 2018. Source: Authors calculation based on the Statistical Yearbook of Nanjing, Suzhou, Wuxi, Changzhou, Nantong, Taizhou, Yangzhou, Zhenjiang, Yancheng, Xuzhou, Huaian, Lianyungang, and Suqian (between 2012 and 2019).

\section{Conclusions and Implications}

This study collected data on the pollution load and gross industrial output of large industries in Jiangsu between 2006 and 2018 to investigate the industrial-transfer-induced changes in pollution load and spatial characteristics of each industry. After deducting the environmental pollution generated by the growth of pre-existing industries in each prefecture-level city, the industrial transfer condition and pollution transfer in each prefecture-level city were estimated, and the following conclusions were made.

First, Jiangsu's prefecture-level cities underwent a volatile change in industrial structure between 2006 and 2018. During this period, industrial transfer exhibited clear spatial hierarchical characteristics. Industries mainly transferred out from the most developed Southern Jiangsu region to its vicinity and then to the Central Jiangsu and Northern Jiangsu regions.

Second, there existed heterogeneities in the factors including scale, structure, and technology of the industries of various prefecture-level cities, and accordingly, the scale effect, structure effect and technology effect also existed in the impact of industrial development on the environment, which resulted in significant spatial differences in the degree of influence of environmental pollution due to the change of industrial structure.

Third, the transfer of pollution intensive industries has led to changes in the industrial structure of the industry transfer-out areas and the industry transfer-in areas, and the corresponding industrial scale has also changed. Therefore, the transfer of pollution intensive industries shows obvious spatial gradient characteristics. In detail, the cities such as Suzhou, Wuxi, and Nanjing have reduced the proportion of polluting enterprises in 
transfer-out areas and improved the environment due to the transfer out of pollution intensive industries; by contrary, the environment pollution in the transfer-in areas including Xuzhou, Huaian, Yancheng, and Taizhou was more severe.

Finally, differences were observed in the destinations of industry and pollution transfer; the textile industry and chemical raw material and chemical products industry mainly transferred to the Central Jiangsu and Northern Jiangsu regions, whereas the paper industry resulted in pollution transfer to cities in the Southern Jiangsu region.

Overall, the industrial spatial pattern of Jiangsu has been significantly regulated in recent years. However, with the regulation of industrial structures, industrial transfer has also changed the scale, structure, and innovation of related industries in the prefecture-level cities of Jiangsu. In the initial period of high-quality development, industrial pollution accompanied with the industrial transfer began to spread to the ecologically fragile areas of Central and Northern Jiangsu areas. The increase in the scale of pollution intensive industries inhibited the role of industrial development in promoting the economy, which is not conducive to the sustainable development of the economy. For this reason, the local government should timely adjust industrial development and environmental protection policies based on the local industrial scale and structure change, so as to enhance the driving force of enterprise scientific and technological innovation as well as enlarge the role of technology effect in environmental protection. Meanwhile, force the industries to transform and upgrade via improving the awareness of residents in environmental protection and reducing the consumption of high-pollution products.

An understanding of environmental effects is conducive to adopting a sustainable development perspective to discuss the environmental problems of industrial transfer. However, due to difficulties in obtaining the necessary data, this study exclusively considered industrial enterprises of a certain scale. Future studies should investigate and elaborate on the classification of industrial enterprises to increase the comprehensiveness of current research findings.

Author Contributions: Conceptualization, G.M. and W.J.; Formal analysis, G.M., W.J. and Y.M.; Funding acquisition, G.M. and W.J.; Investigation, W.J., Y.Z. and Y.M.; Methodology, W.J. and Y.Z.; Project administration, G.M.; Resources, Y.Z.; Software, H.-L.L.; Supervision, G.M.; Validation, W.L.H.; Visualization, W.-L.H.; Writing-review \& editing, H.-L.L., G.M. and W.J. contributed equally to this work. All authors have read and agreed to the published version of the manuscript.

Funding: The Ministry of education of Humanities and Social Science project of China, grant number (18YJA790061); Social Science Foundation of Jiangsu Province, China (18EYB008); Humanity and Social Science Youth foundation of Chinese Ministry of Education, grant number (18YJC790065); National Statistical Science Research Project, China, grant number (2020LY029); The major social science project of universities in Jiangsu Province (2018jdxm002); National Natural Science Foundation of China, grant number (41271135).

Institutional Review Board Statement: Not applicable.

Informed Consent Statement: Not applicable.

Data Availability Statement: Not applicable.

Acknowledgments: We would like to thank anonymous reviewers for their valuable comments and suggestions for improving this paper.

Conflicts of Interest: The authors declare no conflict of interest. 


\section{Appendix A}

Table A1. Industrial transfer in four prefectural-level cities in Jiangsu between 2006 and 2018.

\begin{tabular}{|c|c|c|}
\hline City & Transferred-In Industries & Transferred-Out Industries \\
\hline Nanjing & $\begin{array}{l}\text { Electrical machinery and equipment } \\
\text { manufacturing }(0.0043 \%) \text {; instruments, } \\
\text { meters, and cultural and clerical } \\
\text { machinery }(0.2156 \%) \text {; textile garments, } \\
\text { footwear, and hat products }(0.2037 \%) \text {, } \\
\text { metal products }(0.1313 \%) \text {; production } \\
\text { and supply of electric power and heat } \\
\text { power }(0.0359 \%) ; \text { manufacture of } \\
\text { medicines }(0.0254 \%) \text {; manufacture of } \\
\text { furniture }(0.0195 \%) ; \text { manufacture of } \\
\text { textiles }(0.0138 \%) ; \text { manufacture of paper } \\
\text { and paper products }(0.0112 \%) \text {; } \\
\text { manufacture of leather, fur, feather, and } \\
\text { related products }(0.0089 \%)\end{array}$ & 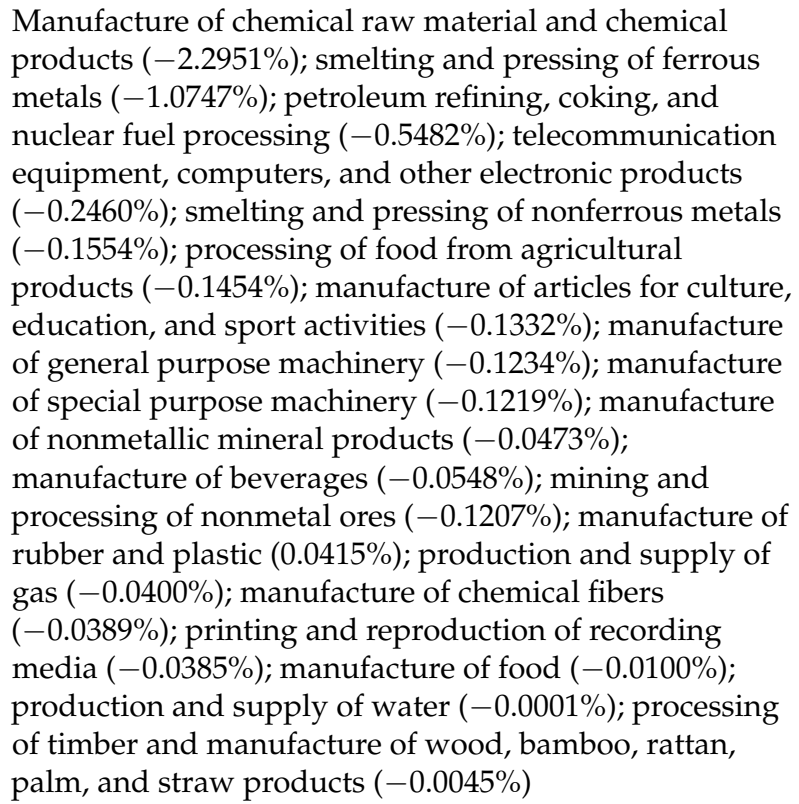 \\
\hline
\end{tabular}

Manufacture of electrical machinery and equipment $(1.0893 \%)$; smelting and pressing of ferrous metals $(0.8821 \%)$; smelting and pressing of nonferrous metals $(0.3313 \%)$; manufacture of communication equipment, computers, and other electronic equipment $(0.1414 \%)$; manufacture of measuring instruments and machinery for cultural activity and office work $(0.1338 \%)$; manufacture of articles for culture, education, and sport activities $(0.0726 \%)$; manufacture of paper and paper products $(0.0544 \%)$; processing of petroleum, coking, and processing of nucleus fuel $(0.0366 \%)$; manufacture of leather, fur, feather, and related products $(0.0321 \%)$; manufacture of food $(0.0313 \%)$; production and supply of gas $(0.0150 \%)$; production and supply of water $(0.0062 \%)$
Manufacture of general purpose machinery $(-0.4838 \%)$; manufacture of special purpose machinery $(-0.4474 \%)$; smelting and pressing of nonferrous metals $(-0.2463 \%)$; manufacture of textile garments, footwear, and hat products $(-0.2284 \%)$; manufacture of rubber and plastic $(-0.1443 \%)$; manufacture of medicines $(-0.0960 \%)$; processing of timber and manufacture of wood, bamboo, rattan, palm, and straw products $(-0.0637 \%)$; manufacture of textiles $(-0.0539 \%)$; production and supply of electric power and heat power $(-0.0453 \%)$; processing of food from agricultural products $(-0.0417 \%)$; printing and reproduction of recording media $(-0.0368 \%)$; manufacture of furniture $(-0.0349 \%)$; mining and processing of nonmetal ores $(-0.0234 \%)$; manufacture of metal products $(-0.0245 \%)$; manufacture of nonmetallic mineral products $(-0.0326 \%)$; manufacture of beverages $(-0.0201 \%)$; manufacture of chemical fibers $(-0.0133 \%)$ 
Table A1. Cont.

\begin{tabular}{|c|c|c|}
\hline City & Transferred-In Industries & Transferred-Out Industries \\
\hline Suzhou & $\begin{array}{l}\text { Manufacture of general purpose } \\
\text { machinery }(0.8408 \%) \text {; manufacture of } \\
\text { chemical fibers }(0.2001 \%) \text {; production and } \\
\text { supply of gas }(0.0597 \%) \text {; manufacture of } \\
\text { food }(0.0488 \%) \text {; manufacture of beverages } \\
(0.0032 \%)\end{array}$ & 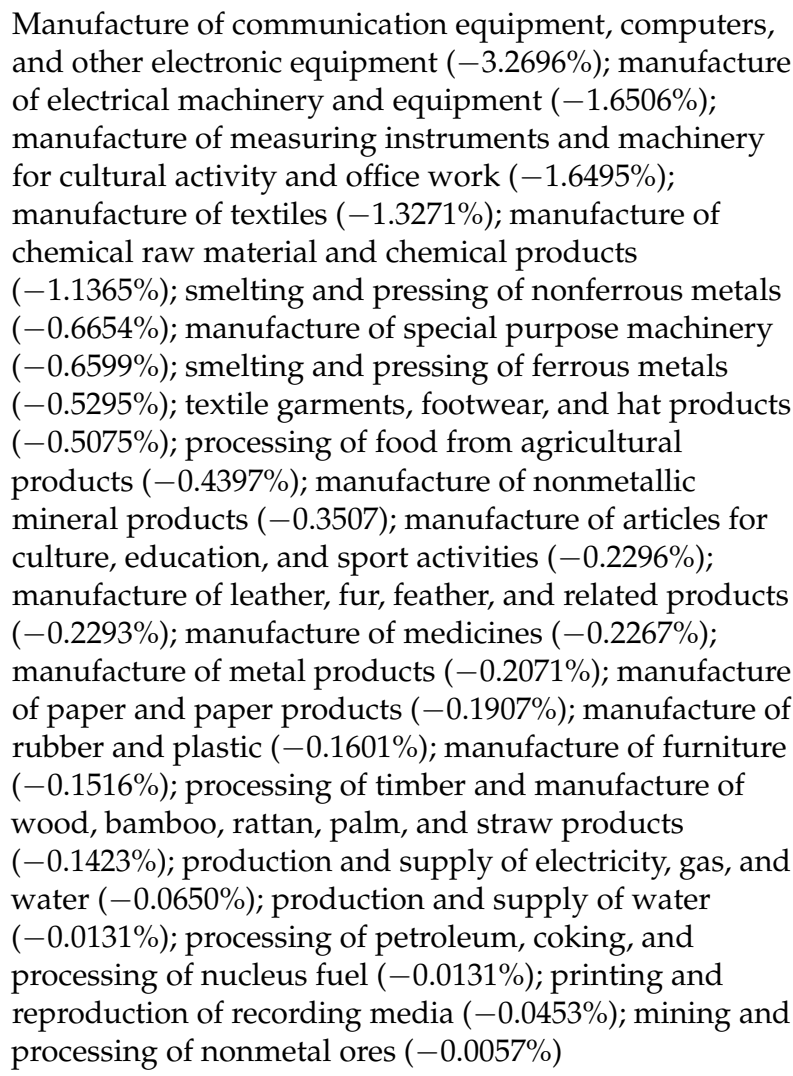 \\
\hline
\end{tabular}

Manufacture of chemical raw material and chemical products (1.2045\%); manufacture of electrocution machinery and equipment (1.0322\%); manufacture of special purpose machinery $(0.9112 \%)$; manufacture of general purpose machinery $(0.7110 \%)$; manufacture of communication equipment, computers, and other electronic equipment $(0.6728 \%)$; manufacture of textiles $(0.4612 \%)$; manufacture of articles for culture, education, and sport activities (0.4507\%); manufacture of measuring instruments

Nantong and machinery for cultural activity and office work $(0.2872 \%)$; manufacture of chemical fibers $(0.1845 \%)$; manufacture of metal products $(0.1724 \%)$; smelting and pressing of nonferrous metals $(0.1582 \%)$; manufacture of medicines $(0.0774 \%)$; smelting and pressing of ferrous metals $(0.0683 \%)$; manufacture of food $(0.0542 \%)$; manufacture of paper and paper products $(0.0522 \%)$; production and supply of electric power and heat power $(0.0350 \%)$; production and supply of gas $(0.0199 \%)$; production and supply of water $(0.0108 \%)$; manufacture of nonmetallic mineral products $(0.0081 \%)$
Processing of petroleum, coking, and nucleus fuel $(-0.0002 \%)$; processing of food from agricultural products $(-0.4384 \%)$; manufacture of textile garments, hats, and footwear $(-0.3387 \%)$; manufacture of rubber and plastic $(-0.0658 \%)$; manufacture of beverages $(-0.0235 \%)$; processing of timber and manufacture of wood, bamboo, rattan, palm, and straw product $(-0.0158 \%)$; manufacture of leather, fur, feather, and related products $(-0.0043 \%)$; manufacture of furniture $(-0.0028 \%)$; printing and reproduction of recording media $(-0.0019 \%)$

Note: Values in parentheses represent the proportion of each industry that transferred within Jiangsu. Source: Authors calculation using the Statistical Yearbook of Jiangsu (between 2007 and 2019). 


\section{References}

1. Arrow, K.; Bolin, B.; Costanza, R.; Dasgupta, P.; Folke, C.; Holling, C.; Jansson, B.-O.; Levin, S.; Mäler, K.-G.; Perrings, C. Economic growth, carrying capacity, and the environment. Environ. Dev. Econ. 1996, 1, 104-110. [CrossRef]

2. Holdren, J.P. Science and technology for sustainable well-being. Science 2008, 319, 424-434. [CrossRef]

3. Yang, Q.; Liu, J.; Zhang, Y. Decoupling agricultural nonpoint source pollution from crop production: A case study of Heilongjiang land reclamation area, China. Sustainability 2017, 9, 1024. [CrossRef]

4. He, C.F.; Zhou, Y.; Zhang, T. Industrial transfer and its environmental effect in China. Urban Environ. Stud. 2014, 1, 34-49.

5. Hanif, I.; Raza, S.M.F.; Gago-de-Santos, P.; Abbas, Q. Fossil fuels, foreign direct investment, and economic growth have triggered $\mathrm{CO}_{2}$ emissions in emerging Asian economies: Some empirical evidence. Energy 2019, 171, 493-501. [CrossRef]

6. Wang, Q.; Kwan, M.-P.; Zhou, K.; Fan, J.; Wang, Y.; Zhan, D. The impacts of urbanization on fine particulate matter (PM 2.5) concentrations: Empirical evidence from 135 countries worldwide. Environ. Pollut. 2019, 247, 989-998. [CrossRef] [PubMed]

7. Raza, S.A.; Shah, N.; Sharif, A. Time frequency relationship between energy consumption, economic growth and environmental degradation in the United States: Evidence from transportation sector. Energy 2019, 173, 706-720. [CrossRef]

8. Mahmood, H.; Furqan, M.; Bagais, O.A. Environmental accounting of financial development and foreign investment: Spatial analyses of East Asia. Sustainability 2019, 11, 13. [CrossRef]

9. Sapkota, P.; Bastola, U. Foreign direct investment, income, and environmental pollution in developing countries: Panel data analysis of Latin America. Energy Econ. 2017, 64, 206-212. [CrossRef]

10. Sarkodie, S.A.; Strezov, V. Effect of foreign direct investments, economic development and energy consumption on greenhouse gas emissions in developing countries. Sci. Total Environ. 2019, 646, 862-871. [CrossRef]

11. Charfeddine, L.; Kahia, M. Impact of renewable energy consumption and financial development on $\mathrm{CO}_{2}$ emissions and economic growth in the MENA region: A panel vector autoregressive (PVAR) analysis. Renew. Energy 2019, 139, 198-213. [CrossRef]

12. Doytch, N.; Uctum, M. Globalization and the environmental impact of sectoral FDI. Econ. Syst. 2016, 40, 582-594. [CrossRef]

13. Liang, F.H. Does foreign direct investment improve the productivity of domestic firms? Technology spillovers, industry linkages, and firm capabilities. Res. Policy 2017, 46, 138-159. [CrossRef]

14. Jin, W.; Mao, G.X.; Liu, S.S.; Wang, C.X. Threshold Effect of FDI and Environmental Regulation on Industrial Water Efficiency. Int. Bus. 2018, 2, 100-112.

15. Zhou, Z.; Zhang, W.; Pan, X.; Hu, J.; Pu, G. Environmental tax reform and the "double dividend" hypothesis in a small open economy. Int. J. Environ. Res. Public Health 2020, 17, 217. [CrossRef]

16. Shan, W.; Wang, J. The effect of environmental performance on employment: Evidence from China's manufacturing industries. Int. J. Environ. Res. Public Health 2019, 16, 2232. [CrossRef]

17. Zhang, C.; Wang, C.; Mao, G.; Wang, M.; Hsu, W.-L. An empirical study on the ecological economy of the Huai river in China. Water 2020, 12, 2162. [CrossRef]

18. Yoon, S.; Nadvi, K. Industrial clusters and industrial ecology: Building 'eco-collective efficiency' in a South Korean cluster. Geoforum 2018, 90, 159-173. [CrossRef]

19. Sun, L.; Wang, Q.; Zhang, J. Inter-industrial carbon emission transfers in China: Economic effect and optimization strategy. Ecol. Econ. 2017, 132, 55-62. [CrossRef]

20. Yang, X.; Li, C. Industrial environmental efficiency, foreign direct investment and export—Evidence from 30 provinces in China. J. Clean. Prod. 2019, 212, 1490-1498. [CrossRef]

21. Wang, J.; Yang, F.; Zhang, X.; Zhou, Q. Barriers and drivers for enterprise energy efficiency: An exploratory study for industrial transfer in the Beijing-Tianjin-Hebei region. J. Clean. Prod. 2018, 200, 866-879. [CrossRef]

22. Kang, Y.-Q.; Zhao, T.; Yang, Y.-Y. Environmental Kuznets curve for $\mathrm{CO}_{2}$ emissions in China: A spatial panel data approach. Ecol. Indic. 2016, 63, 231-239. [CrossRef]

23. Hu, J.; Liu, Y.; Fang, J.; Jing, Y.; Liu, Y.; Liu, Y. Characterizing pollution-intensive industry transfers in China from 2007 to 2016 using land use data. J. Clean. Prod. 2019, 223, 424-435. [CrossRef]

24. Yin, J.; Zheng, M.; Li, X. Interregional transfer of polluting industries: A consumption responsibility perspective. J. Clean. Prod. 2016, 112, 4318-4328. [CrossRef]

25. Li, Y.; Sun, L.; Zhang, H.; Liu, T.; Fang, K. Does industrial transfer within urban agglomerations promote dual control of total energy consumption and energy intensity. J. Clean. Prod. 2018, 204, 607-617. [CrossRef]

26. Xiaohua, S.; Xu, G.; Yun, W. Industrial relocation, elements agglomeration and regional economic development. Manag. World 2018, 34, 47-62. [CrossRef]

27. Wei, D.; Liu, Y.; Zhang, N. Does industry upgrade transfer pollution: Evidence from a natural experiment of Guangdong province in China. J. Clean. Prod. 2019, 229, 902-910. [CrossRef]

28. Chen, L.; Xu, L.; Yang, Z. Accounting carbon emission changes under regional industrial transfer in an urban agglomeration in China's Pearl River Delta. J. Clean. Prod. 2017, 167, 110-119. [CrossRef]

29. Xu, J.; Zhang, M.; Zhou, M.; Li, H. An empirical study on the dynamic effect of regional industrial carbon transfer in China. Ecol. Indic. 2017, 73, 1-10. [CrossRef]

30. Liu, C.; Hong, T.; Li, H.; Wang, L. From club convergence of per capita industrial pollutant emissions to industrial transfer effects: An empirical study across 285 cities in China. Energy Policy 2018, 121, 300-313. [CrossRef] 
31. Chen, W.; Shen, Y.; Wang, Y.; Wu, Q. The effect of industrial relocation on industrial land use efficiency in China: A spatial econometrics approach. J. Clean. Prod. 2018, 205, 525-535. [CrossRef]

32. Grossman, G.M.; Krueger, A.B. Economic growth and the environment. Q. J. Econ. 1995, 110, 353-377. [CrossRef]

33. Yang, J.; Li, X.; Xiong, Z.; Wang, M.; Liu, Q. Environmental pollution effect analysis of lead compounds in china based on life cycle. Int. J. Environ. Res. Public Health 2020, 17, 2184. [CrossRef] [PubMed]

34. Xu, H.; Hsu, W.-L.; Meen, T.-H.; Zhu, J.H. Can higher education, economic growth and innovation ability improve each other? Sustainability 2020, 12, 2515. [CrossRef] 